\title{
Custos para o setor público na atuação como mercado para agricultura familiar no PAA em Toledo-PR
}

\section{Costs for the public sector in the action as a market for family agriculture in the PAA in Toledo-PR}

Karine Daniele Byhain de Souza-Mestra pelo Programa de Pós-Graduação em Administração (PPGA) da Universidade Estadual do Oeste do Paraná. Agente universitário da Universidade Estadual do Oeste do Paraná. E-mail: karine.dbs@gmail.com

Edison Luiz Leismann - Doutor em Economia Aplicada pela Universidade Federal de Viçosa. Professor da Universidade Estadual do Oeste do Paraná. E-mail: elleismann@ gmail.com

Loreni Teresinha Brandalise - Doutora em Engenharia de Produção pela Universidade Federal de Santa Catarina. Docente do curso de graduação em Administração e do Programa de Mestrado Profissional em Administração da Universidade Estadual do Oeste do Paraná - campus de Cascavel. E-mail: lorenibrandalise@gmail.com

\section{Resumo}

Este estudo teve como temática a verificação dos custos para o setor público na atuação como mercado para a produção da agricultura familiar na execução do Programa de Aquisição de Alimentos no município de Toledo-PR. A metodologia adotada foi a coleta de dados por meio da pesquisa documental nos processos licitatórios do município e em websites governamentais, verificando-se os valores pagos em licitações e por meio do programa em 2015. A análise dos dados foi realizada com a aplicação da estatística descritiva que identificou que o custo para o setor público, ao comprar produtos da agricultura familiar, é inferior ao adquirir produtos por meio de licitação, não havendo subsídio. Concluiu-se que é necessário uma revisão da metodologia de formação de preços dos produtos do PAA, objetivando estimular a participação dos agricultores familiares no programa de aquisição de alimentos.

\section{Palavras-chave}

Programa de Aquisição de Alimentos. Agricultura Familiar. Custos para o Setor público.

\begin{abstract}
This study deals with the verification of costs for the public sector as a market for the production of family farming in the execution of the Food Acquisition Program in the city of Toledo-PR. The methodology adopted was the collection of data through documental research in the bidding processes of the municipality and in government websites, verifying the amounts paid in bids and through the program in 2015. The analysis of the data was performed with the application of statistics Descriptive study that identified that the cost to the public sector, when buying products from family agriculture, is lower than buying products through a bidding process, with no subsidy. It was concluded that a review of the methodology of price formation of the PAA products is necessary, aiming to stimulate the participation of the family farmers in the food acquisition program.
\end{abstract}

\section{Keywords}

Food Acquisition Programme. Family Agriculture. Costs to the Public Sector. 


\section{INTRODUÇÃO}

A agricultura tem destaque no Brasil como uma das principais fontes econômicas do país. Dados da Empresa Brasileira de Pesquisa Agropecuária (EMBRAPA, 2014) demonstram que este segmento atinge 4,3 milhões de unidades produtivas ( $84 \%$ do total) e 80.250 .453 hectares (25\% da área total), cuja produção é destinada, em sua maioria, para as populações urbanas e locais.

A relevância deste setor também está pautada nas práticas agrícolas familiares, que podem ter alta produtividade, sustentabilidade, e ser dinâmicas, quesitos estes que contribuem para a segurança alimentar e nutricional (PLOEG, 2014). Em função desta importância, a atividade agrícola gera efeitos sobre o desenvolvimento territorial, pois causa impactos econômicos e produz reflexos em outros setores da economia (MERA, 2011).

Para incentivar a agricultura familiar e promover o acesso à alimentação, foi criado em 2003 pelo governo federal, por meio da Lei no 10.696 (2003), art. 19, o Programa de Aquisição de Alimentos (PAA). A partir da inclusão do PAA no dispositivo legal, o programa possibilitou o acesso aos alimentos das populações em situação de insegurança alimentar e também viabilizou a comercialização dos produtos da agricultura familiar.

De acordo com Grisa (2012), o PAA foi a consequência de um conjunto de reflexões e de reivindicações realizadas por atores da sociedade civil e por gestores públicos, figuras estas que trabalham nos assuntos da fome e da segurança alimentar desde a década de 1990, além de convergir com as solicitações das organizações da agricultura familiar por ações de apoio à comercialização da produção agrícola, demandas existentes desde a década de 1970.

Desde a sua implementação o PAA teve muitos avanços, pois conforme Ferreira et al (2014), o programa é uma importante ferramenta de fortalecimento da agricultura familiar. Por outro lado, há dificuldades enfrentadas tanto pelos agricultores quanto pelos órgãos públicos participantes do PAA. Soares et al (2013) mencionam limitações na execução do programa, como por exemplo, falta de articulação entre produção e consumo, dificuldades na logística e recebimento dos produtos. Além disso, Plein e Fillipi (2012) citam problemáticas como a forma de pagamento e a burocracia, que levam produtores ao ponto de desistir do programa.

Apesar dos obstáculos existentes, de acordo com a Secretaria de Estado de Educação (SEED, 2015), o estado do Paraná tem se caracterizado como referência nacional na compra de alimentos produzidos pela agricultura familiar 
para destinação à merenda escolar. As compras são gerenciadas com a utilização de um sistema eletrônico desenvolvido no estado e utilizado pela SEED, sendo que em 2015 foram investidos cerca de $\mathrm{R} \$ 45$ milhões na compra de alimentos da agricultura familiar para a merenda escolar, de 128 instituições de agricultores familiares, num total aproximado de 15.487 toneladas de produtos.

Da mesma forma, na execução do PAA, o município de Toledo tem dados representativos, pois gerenciou em 2015 o equivalente a 23,42\% dos recursos destinados ao estado do Paraná, o que correspondeu a $\mathrm{R} \$$ 574.637,94, período no qual foram adquiridos $97.604 \mathrm{~kg}$ de alimentos de 127 agricultores (SAGI, 2016).

Tendo em vista os valores envolvidos na execução do PAA no município de Toledo, o objetivo deste artigo consiste em dimensionar os custos para o setor público como participante do programa na atuação e como garantidor de mercado para a produção da agricultura familiar.

Este estudo está estruturado em cinco seções: introdução; referencial teórico, contendo os conteúdos que o embasaram; seguido da metodologia na terceira seção; a quarta seção apresenta a análise dos resultados; finalizando com as considerações finais.

Cabe mencionar que este artigo aborda parte de um estudo realizado para desenvolvimento de dissertação que avaliou o Programa de Aquisição de Alimentos (PAA) no ano de 2016, como fator de promoção da sustentabilidade da agricultura familiar, por meio dos agricultores participantes do programa gerenciado pelo município de Toledo, no estado do Paraná.

\section{POLÍTICAS PÚBLICAS PARA AGRICULTURA}

Esta seção aborda os assuntos referentes a políticas públicas para a agricultura, para a agricultura familiar, o Programa de Aquisição de Alimentos (PAA) e suas modalidades.

A política agrícola no Brasil passou a ser acionada de maneira estruturada desde os anos 1960, quando ocorreu a utilização de instrumentos para interferência nos mercados de produtos, fatores de produção e insumos de crédito. Naquela época, os estímulos para o setor agrícola eram interpretados como uma compensação necessária à política macroeconômica que favorecia a industrialização em função da atividade agropecuária (GASQUES; VIEIRA FILHO; NAVARRO, 2010).

Contudo, Coelho (2012) expõe que já em meados da década de 1930 foi implantanda uma medida que pode ser considerada como primeiro passo para a prática de uma política agrícola nacional, na qual ocorreu a transferência de 
responsabilidade da política cafeeira para o governo federal, com a criação do Conselho Nacional do Café.

A década de 1960 foi de grande importância para as políticas públicas da agricultura, período em que o Brasil promoveu um ambicioso programa de modernização da agricultura, com destaque ao crédito rural que viabilizou as transformações que se seguiram. No ano de 1965 o governo implementou o Sistema Nacional de Crédito Rural para financiamento agrícola. Essa política produziu transformações profundas no setor quanto ao emprego, tecnologia, composição da produção de uso e posse da terra (CARVALHO, 2001).

Em 1973, o Estado criou a Empresa Brasileira de Assistência Técnica e Extensão Rural (EMBRATER) com o objetivo de aumentar a produção de alimentos e melhorar as condições de vida da população rural. Em 1974 a EMBRATER e a Empresa Brasileira de Pesquisa Agropecuária (EMBRAPA), tornaram-se os principais instrumentos básicos, de caráter executivo, para desenvolver a agropecuária nacional (ROMANIELLO; ASSIS, 2015).

Carvalho (2001) acrescenta que no final da década de 1970, a estratégia de modernização da agricultura começou a ser abandonada, em função da crise fiscal que o país enfrentava. Com a crise da dívida pública, no final da década de 1980, Chadad, Jank e Nakahodo (2006) assinalam que o governo reduziu os gastos com políticas agrícolas. Neste cenário, o país deixou de formar estoques reguladores, de garantir preços mínimos, de controlar preços ao longo das cadeias produtivas e, nesta época, ocorreu a liberação comercial e integração econômica, principalmente no âmbito do Mercosul.

Essas mudanças proporcionaram a modernização da agricultura, o aumento da competitividade e a inserção internacional. Contudo, após a redução do apoio das políticas públicas, o produtor nacional ficou exposto aos riscos de produção, preço e crédito da atividade. Em 1995, o país enfrentou a primeira crise da dívida agrícola (CHADAD; JANK; NAKAHODO, 2006).

Nesta conjuntura, desde 1995, a política agrícola passou a ter novo foco privilegiando a reforma agrária e a agricultura familiar como forma de inclusão social. De acordo com Mueller (2010), entre 1999 e 2004 o agronegócio passou por um período de prosperidade, no qual os lucros do setor eram elevados, porém, em 2005 foram sentidos impactos da estiagem e surtos de infestações de pragas e fungos: o setor entrou em crise. Neste período o governo aprovou pacotes de ajuda voltados ao alívio desta nova crise, como resultado, o país teve safra recorde de 2006-2007.

O estudo realizado por Strassburg et al (2015) identificou que as políticas agrícolas e estruturantes aplicadas no Brasil incentivaram a segurança alimentar e 
nutricional, além de possibilitar a ampliação da discussão sobre o desenvolvimento rural. No contexto do desenvolvimento rural, o mesmo agrega a visão agrícola e produtivista e, por meio deste, surge uma alternativa para o desenvolvimento dos pequenos agricultores.

\section{POLÍTICAS PÚBLICAS PARA AGRICULTURA FAMILIAR}

As políticas públicas voltadas para a agricultura familiar devem diminuir dificuldades como baixa capitalização, obtenção de crédito e proporcionar acesso aos mercados modernos pela adoção de novas tecnologias (JUNQUEIRA; LIMA, 2008).

Ainda que a agricultura familiar tenha relevante importância, historicamente este setor não foi contemplado por meio de políticas públicas, tendo em vista que os recursos estatais eram direcionados para as grandes propriedades. Em função dos estímulos realizados pelo Estado, foi proporcionada a modernização e a reprodução da grande propriedade monocultora, o que deixou a agricultura familiar em lugar inferior na sociedade (SOUZA-ESQUERDO; BERGAMASCO, 2014).

Somente em 1996 a lacuna de descaso com a agricultura familiar começou a ser sanada, com a criação do Programa Nacional de Fortalecimento da Agricultura Familiar (PRONAF). A criação deste programa ocorreu em função de mobilizações sociais efetuadas por movimentos sociais da agricultura familiar e também em decorrência de mudanças nos estudos rurais, que começaram a enfatizar a permanência do homem no campo e a importância da agricultura familiar nos países desenvolvidos (ABRAMOVAY, 2007).

Este programa, que tem vigência até a atualidade, passou por transformações desde que foi criado, e consiste em "estimular a geração de renda e melhorar o uso da mão de obra familiar, meio de financiamento de atividades e serviços rurais e agropecuários e não agropecuários desenvolvidos em estabelecimento rural ou em áreas comunitárias" (BANCO CENTRAL DO BRASIL, 2015).

Para execução do Pronaf foram criados grupos do crédito para garantir tratamento diferenciado aos diferentes produtores, onde tais grupos têm como critério definidor o nível de renda familiar bruta anual e, assim, a cada nível são oferecidas condições de financiamento diferenciadas (prazos, juros, limites, descontos por adimplência). Assim, os grupos de renda maior acessam o crédito PRONAF apenas nas condições próximas ao crédito rural da agricultura de maior escala (MENDONÇA, 2008). 
Com a criação do PRONAF teve início a criação de uma série de medidas destinadas a fortalecer e garantir a produção agrícola dos produtores familiares. Neste contexto, cita-se a concepção, em 2004, do Seguro da Agricultura Familiar (SEAF) e do Programa de Garantia de Preço da Agricultura Familiar (PGPAF) em 2006 e a retomada da Assistência Técnica e Extensão Rural (ATER) pública em anos posteriores, para demonstrar estas ações (GRISA; SCHNEIDER, 2014).

Em 2003 foi desenvolvido mais um projeto que envolve diretamente a agricultura familiar, conforme Grisa (2012), o Projeto Fome Zero propôs um conjunto de políticas estruturais que objetivavam o aumento da renda e da oferta de alimentos básicos, contido neste projeto está o Programa de Aquisição de Alimentos (PAA).

Outra conquista da agricultura familiar foi a Lei $\mathrm{n}^{\mathrm{a}}$ 11.326/2006 que estabelece diretrizes para a formulação da política nacional da agricultura familiar e empreendimentos familiares rurais, e prevê crédito, assistência técnica, comercialização de seguro agrícola e igualdade para as mulheres da agricultura familiar (BRASIL, 2006).

\section{PROGRAMA DE AQUISIÇÃO DE ALIMENTOS (PAA)}

Em 2003, foi implementado o Programa Fome Zero, que dentre outros, objetivava o aumento da disponibilidade de alimentos a baixos preços e também o maior acesso da população necessitada a uma alimentação de qualidade. Este programa se transformou na maior estratégia do governo para dirigir as políticas econômicas e sociais (SILVA; DEL GROSSI; FRANÇA, 2010).

Este programa inicialmente compreendeu programas estruturais, tais como reforma agrária, fortalecimento da agricultura familiar, programa de superação de analfabetismo, programa de geração de emprego, e programas específicos, dentre os quais englobou restaurantes populares, bancos de alimentos, ampliação da alimentação escolar, programa cartão de alimentação emergencial e educação alimentar (SILVA; DEL GROSSI; FRANÇA, 2010).

Como parte das ações dos programas estruturais, foi desenvolvido o Programa de Aquisição de Alimentos, de acordo com a Lei nº 10.696 de 2003, no art. 19, compreende:

I - incentivar a agricultura familiar, promovendo a sua inclusão econômica e social, com fomento à produção com sustentabilidade, ao processamento de alimentos e industrialização e à geração de renda; 
II - incentivar o consumo e a valorização dos alimentos produzidos pela agricultura familiar;

III - promover o acesso à alimentação, em quantidade, qualidade e regularidade necessárias, das pessoas em situação de insegurança alimentar e nutricional, sob a perspectiva do direito humano à alimentação adequada e saudável;

IV - promover o abastecimento alimentar, que compreende as compras governamentais de alimentos, incluída a alimentação escolar;

$\mathrm{V}$ - constituir estoques públicos de alimentos produzidos por agricultores familiares;

VI - apoiar a formação de estoques pelas cooperativas e demais organizações formais da agricultura familiar; e

VII - fortalecer circuitos locais e regionais e redes de comercialização (BRASIL, 2003).

A partir da instituição desta lei, verifica-se que o programa contempla demandas de acesso aos alimentos das populações em situação de insegurança alimentar e também abrange as necessidades dos agricultores familiares para comercialização de seus produtos.

Para implantação do programa foi criado o Grupo Gestor do PAA que é coordenado pelo Ministério do Desenvolvimento Social e Combate à Fome (MDS) e é composto pelo Ministério do Planejamento, Orçamento e Gestão, Ministério do Desenvolvimento Agrário (MDA), Ministério da Agricultura, Pecuária e Abastecimento e Ministério da Fazenda, que estabelecem as diretrizes do programa, sendo que o grupo gestor tem como objetivo principal orientar e acompanhar a execução do PAA, normatizando-o por meio de suas resoluções (MDS, 2012).

Tendo como base as orientações do programa, sua aplicação ocorreu em nível federal, estadual e municipal, sendo financiado pelo MDS e MDA, que disponibilizam recursos orçamentários e financeiros. O governo realiza as compras por meio das modalidades existentes, que são Compra Direta da Agricultura Familiar, Compra Antecipada Especial da Agricultura Familiar; Compra Antecipada da Agricultura Familiar e Compra Direta Local da Agricultura Familiar (MAT'TEI, 2007).

Estas compras por parte das instituições públicas foram desburocratizadas, ao passo que a legislação proporcionou a compra direta, sem a realização de processo licitatório, possibilitando a presença do Estado para apoiar a comercialização da produção da agricultura familiar (CONAB, 2003).

Os agricultores familiares podem participar do programa diretamente ou por intermédio de cooperativas familiares, desde que se enquadrem no PRONAF, 
sendo a identificação deste cadastro realizada por meio da Declaração de Aptidão ao Pronaf (MDS, 2015).

Visando ampliar os mercados para comercialização dos produtos da agricultura familiar, o Grupo Gestor do PAA emitiu a Resolução 50/2012, que institui uma nova modalidade de compra dos produtos, as Compras Institucionais, permitindo que os órgãos públicos que forneçam alimentação também façam aquisição por meio do programa com recursos próprios e com dispensa do procedimento licitatório (MDS, 2013). Em 2015 foi criada mais uma modalidade, a aquisição de sementes.

\section{MODALIDADES DO PAA}

O Programa de Aquisição de Alimentos está estruturado em seis modalidades: compra para doação simultânea; formação de estoques; compra direta da agricultura familiar; incentivo para a produção e consumo de leite; compra institucional; e aquisição de sementes.

$\mathrm{Na}$ modalidade compra da agricultura familiar para doação simultânea os produtos adquiridos dos agricultores familiares são doados às pessoas em insegurança alimentar, por meio da rede socioassistencial ou equipamentos públicos de segurança alimentar e da rede pública e filantrópica de ensino.

Em outra modalidade, apoio à formação de estoques pela agricultura familiar (CPR Estoque), ocorre o apoio financeiro para a constituição de estoques de alimentos por organizações da agricultura familiar, para posterior comercialização e devolução de recursos ao poder público.

Já na modalidade Compra Direta da Agricultura Familiar (CDAF), acontece a compra de produtos com a finalidade de sustentar preços (MDS, 2015). Incentivo à produção e ao consumo de leite (PAA Leite) é a modalidade na qual ocorre a aquisição de leite de vaca e leite de cabra de agricultores familiares dos estados da região Nordeste e também no norte de Minas Gerais, com sua distribuição, gratuita, a famílias que estejam em situação de vulnerabilidade social.

$\mathrm{Na}$ modalidade compra institucional, órgãos da União, Estados, Distrito Federal e Municípios podem comprar alimentos da agricultura familiar, com seus próprios recursos financeiros, dispensando-se a licitação, para atendimento às demandas de consumo de alimentos. Poderão ser abastecidos hospitais, quartéis, presídios, restaurantes universitários, refeitórios de creches e escolas filantrópicas, entre outros.

Por fim, a modalidade PAA Sementes realiza a compra de sementes de organizações da agricultura familiar detentoras da Declaração de Aptidão ao 
Pronaf (DAP Jurídica), e as destina a agricultores familiares, conforme a demanda dos órgãos parceiros (MDS, 2015).

Com o objetivo de apresentar informações sobre o PAA, o MDS desenvolveu o site PAA DATA que disponibiliza dados sobre o programa considerando seus executores: CONAB, estados e municípios nas modalidades compra com doação simultânea, formação de estoques, compra direta, PAA leite e, a partir da 2015, a modalidade aquisição de sementes (SAGI, 2016). A Tabela 1 mostra os dados das ações executadas pelo PAA entre os anos de 2011 e 2015 .

Tabela 1 - Dados executados pelo PAA entre 2011 e 2015

\begin{tabular}{c|c|c|r}
\hline Ano & $\begin{array}{c}\text { Parte superior do } \\
\text { formulário } \\
\mathbf{N}^{\mathbf{0}} \text { de Agr. } \\
\text { Fornecedores }\end{array}$ & $\begin{array}{c}\text { Parte superior do } \\
\text { formulário } \\
\text { Recursos }(\mathbf{R} \$)\end{array}$ & $\begin{array}{c}\text { Parte superior do } \\
\text { formulário } \\
\text { Produtos (Kg) }\end{array}$ \\
\hline 2011 & 160.011 & $\mathrm{R} \$ 667.325 .490,15$ & $517.921 .881,11$ \\
\hline 2012 & 185.979 & $\mathrm{R} \$ 839.217 .997,38$ & $529.033 .665,31$ \\
\hline 2013 & 96.912 & $\mathrm{R} \$ 443.185 .235,52$ & $280.175 .457,02$ \\
\hline 2014 & 113.727 & $\mathrm{R} \$ 583.838 .845,62$ & $336.155 .540,63$ \\
\hline 2015 & 95.871 & $\mathrm{R} \$ 555.429 .848,06$ & $289.827 .170,98$ \\
\hline
\end{tabular}

Fonte: SAGI (2016).

As informações constantes na Tabela 1 demonstram a importância do programa em função do total de agricultores participantes, recursos destinados e quantidades comercializadas. Nos três primeiros anos do PAA, a média de agricultores era de 60 mil produtores, sendo que entre 2006 a 2011 a média foi para 150 mil participantes, com mais de 1,3 milhão de operações em compra de alimentos, num total de $\mathrm{R} \$ 5,3$ bilhões de recursos investidos no período de 10 anos, segundo o Ministério do Desenvolvimento Agrário (MDA, 2013).

\section{PROCEDIMENTOS METODOLÓGICOS}

Para o desenvolvimento do trabalho, foi realizada revisão bibliográfica, que abordou os assuntos: políticas públicas para agricultura, políticas públicas para agricultura familiar, Programa de Aquisição de Alimentos (PAA) (modalidades do PAA). Também foi efetuada pesquisa documental, para obter informações em sites governamentais sobre os números operacionalizados pelo PAA. Conforme Godoy (1995a), a pesquisa documental é constituída pelos documentos que ainda 
não receberam tratamento analítico e que podem ser reexaminados podendo sofrer novas interpretações.

$\mathrm{Na}$ abordagem foi adotada a metodologia quantitativa e qualitativa. Em estudos quantitativos o pesquisador faz medições objetivas e quantificação dos resultados, ele busca evitar distorções na análise e interpretação dos dados, obtendo uma margem de segurança em relação ao que é obtido (GODOY, 1995b). As análises também têm aspecto qualitativo, porque a pesquisa qualitativa considera informações descritivas sobre pessoas, lugares e processos, a partir dos quais o pesquisador busca a compreensão da situação em análise e procura entender o cenário de acordo com as perspectivas dos sujeitos.

Quanto aos objetivos, a pesquisa caracteriza-se como descritiva, pois os dados coletados passaram por análise estatística. Segundo Gil (1999), as pesquisas descritivas têm como finalidade principal a descrição das características de determinada população ou o estabelecimento de relações entre variáveis, sendo que uma das características mais significativas consiste na utilização de técnicas padronizadas de coleta de dados.

Os procedimentos da pesquisa consistem em levantamento estatístico, sendo que para análise dos dados foi aplicada a estatística descritiva. Neste tipo de estudo a amostra é determinada com base em procedimentos estatísticos, sendo que o conhecimento direto da realidade, economia, rapidez e quantificação estão entre as principais vantagens do procedimento, no qual o estudo descritivo é o mais indicado para esta modalidade de pesquisa (GIL, 2002).

Foi efetuada pesquisa documental no ano de 2015, para obter informações em sites governamentais sobre os produtos licitados e valores pagos em produtos similares aos adquiridos por meio do programa, verificando os custos para o setor público na atuação como mercado a produção da agricultura familiar, por meio da análise dos valores pagos nos produtos adquiridos em processos licitatórios, comparando-os com os valores pagos via PAA.

\section{ANÁLISE E DISCUSSÃO DOS DADOS}

Em 2015, o município de Toledo-PR adquiriu R \$ 574.637,94 em alimentos produzidos pela agricultura familiar, por meio do PAA, com um total de 97.604,04 $\mathrm{kg}$ de produtos. Ao todo foram beneficiadas 15 entidades da cidade, conforme demonstra o Quadro 1. 
Quadro 1 - Entidades beneficiadas pelo PAA em Toledo-PR em 2015

\begin{tabular}{|l|l|}
\hline \multicolumn{1}{|c|}{ Entidade } & \multicolumn{1}{c|}{ Tipo de atividade } \\
\hline Sociedade Batista de Beneficência Tabea & Abrigos/Casas/Albergues \\
\hline $\begin{array}{l}\text { Assoc. de Pais e Amigos dos } \\
\text { Excepcionais de Toledo }\end{array}$ & $\begin{array}{l}\text { Instituições de amparo aos portadores de } \\
\text { necessidades especiais }\end{array}$ \\
\hline $\begin{array}{l}\text { Grupo Espirita Fraternidade - Albergue } \\
\text { Alan Kardec }\end{array}$ & Abrigos/Casas/Albergues \\
\hline Restaurante Popular da Vila Paulista & Restaurantes/Cozinhas \\
\hline $\begin{array}{l}\text { Associação Promocional e Assistencial } \\
\text { de Toledo }\end{array}$ & Abrigos/Casas/Albergues \\
\hline $\begin{array}{l}\text { Prov Bras Congreg Irmãs Filhas Car S } \\
\text { Vicente Paulo }\end{array}$ & $\begin{array}{l}\text { Instituições de amparo a criança e ao } \\
\text { adolescente }\end{array}$ \\
\hline Casa de Maria & $\begin{array}{l}\text { Instituições de amparo a criança e ao } \\
\text { adolescente }\end{array}$ \\
\hline Centro Comunitário e Social Dorcas & $\begin{array}{l}\text { Instituições de amparo a criança e ao } \\
\text { adolescente }\end{array}$ \\
\hline $\begin{array}{l}\text { Rest Popular do Jd. Santa Clara (Europa, } \\
\text { América) }\end{array}$ & Restaurantes/Cozinhas \\
\hline $\begin{array}{l}\text { Restaurante Popular da Vila Boa } \\
\text { Esperança }\end{array}$ & Restaurantes/Cozinhas \\
\hline Restaurante Popular do Jardim Coopagro & Restaurantes/Cozinhas \\
\hline $\begin{array}{l}\text { Centro Beneficente de Ed. Infantil Ledi } \\
\text { Maas Lions }\end{array}$ & $\begin{array}{l}\text { Instituições de amparo a criança e ao } \\
\text { adolescente }\end{array}$ \\
\hline $\begin{array}{l}\text { APADA Assoc.Pais, Amigos, Def. } \\
\text { Auditivos e Surdos }\end{array}$ & $\begin{array}{l}\text { Instituições de amparo aos portadores de } \\
\text { necessidades especiais }\end{array}$ \\
\hline $\begin{array}{l}\text { Centro Social e Educ. Aldeia Infantil } \\
\text { Betesda }\end{array}$ & $\begin{array}{l}\text { Instituições de amparo a criança e ao } \\
\text { adolescente }\end{array}$ \\
\hline $\begin{array}{l}\text { Restaurante Popular do Jardim Sao } \\
\text { Francisco }\end{array}$ & Restaurantes/cozinhas \\
\hline
\end{tabular}

Fonte: Elaborado pelos autores, 2016.

Ao analisar as entidades beneficiadas, destaca-se o destino dos alimentos para os restaurantes populares. De acordo com Zanini e Schneider (2015) havia no Paraná, em 2015, 14 restaurantes populares, instalados nos municípios de Londrina (1), Cascavel (1), Toledo (5), Curitiba (4), Ponta Grossa (1), Paranaguá (1), Maringá (1) e Guarapuava (1), contudo apenas as cidades com mais de 100 mil habitantes podem ser beneficiadas com o programa, sendo que Toledo é o município com mais unidades em todo o estado. Os autores complementam que por meio do PAA, os restaurantes populares possibilitam acesso à alimentação saudável com baixo custo à população, e ainda, estimulam e fortalecimento da 
produção local de alimentos provenientes da agricultura familiar do município. A Tabela 2 demonstra os produtos adquiridos e quantidades por meio do PAA em Toledo no ano de 2015.

Tabela 2 - Produtos e quantidades adquiridas pelo PAA em Toledo no ano de 2015

\begin{tabular}{|c|c|c|c|}
\hline Produtos & $\begin{array}{c}\text { Qtde PAA } \\
\text { Toledo } 2015\end{array}$ & Produtos & $\begin{array}{c}\text { Qtde PAA } \\
\text { Toledo } 2015\end{array}$ \\
\hline Abobrinha conv. & 214 & Maçã conv. & 1785 \\
\hline Acelga & 1669,3 & Macarrão caseiro & 2202 \\
\hline Alface conv. & 4793,8 & Mel de abelha conv. & 168 \\
\hline Alface orgânico & 165 & Milho verde conv. & 81 \\
\hline Almeirão conv. & 3013,7 & Nabo & 274 \\
\hline Almeirão orgânico & 30 & Pão caseiro integral & 90 \\
\hline Batata doce & 6024,7 & Pão caseiro sovado & 1604 \\
\hline Beterraba conv. & 1134,1 & Pão colonial & 317,89 \\
\hline Bolacha caseira & 920 & Pepino conv. & 414 \\
\hline Brócolis conv. & 324,6 & Rabanete & 586,4 \\
\hline Carne bovina dianteira & 20135 & $\begin{array}{l}\text { Raiz de mandioca } \\
\text { congelada sem casca }\end{array}$ & 5079,8 \\
\hline Carne bovina traseira & 20135 & Repolho conv. & 5698,1 \\
\hline Carne suína & 8911 & Repolho orgânico & 1002,5 \\
\hline Cebolinha verde conv. & 422,15 & Rúcula conv. & 258 \\
\hline Cenoura conv. & 2028,2 & Salsa conv. & 494,7 \\
\hline Chicória & 2091,3 & Salsa orgânico & 12 \\
\hline Chicória orgânico & 79 & Suco de uva integral & 1384 \\
\hline Chuchu conv. & 945,5 & Tomate & 48 \\
\hline Conserva de vegetais & 36 & Vinagre colonial & 800 \\
\hline Couve flor conv. & 669 & Total & $97.604,04$ \\
\hline Couve manteiga conv. & 866,3 & & \\
\hline Cuca caseira & 673 & & \\
\hline
\end{tabular}

Fonte: SAGI (2016).

O valor total dos produtos adquiridos pelo programa executado pelo município de Toledo representa $23,42 \%$ do total de recursos operacionalizados no estado do Paraná, por meio de dez municípios que participam do programa. O PAA executado pelo município de Toledo-PR adquire 55 tipos de produtos, destes 38 são olerícolas, entre os quais 14 tipos podem ser adquiridos tanto na produção convencional quanto na orgânica.

Para verificar os custos do setor público na aquisição de produtos da agricultura familiar foram coletados os valores pagos por produtos similares em 
processos licitatórios, contudo não foram localizadas licitações para aquisição de produtos orgânicos, além de não terem sido encontradas licitações para compra de acelga convencional, chicória convencional, nabo convencional, pão caseiro integral, pão colonial e rabanete convencional. Assim, foi comparado o valor pago no PAA com o valor pago em licitaçao de 35 itens.

Cabe mencionar que os valores pagos pelos produtos adquiridos por meio do PAA são baseados nos preços divulgados pela CONAB. Para carnes e panificados os valores são definidos por meio de pesquisa de preços local em mercado atacadista. A Tabela 3 demonstra a relação entre produtos e respectivos preços pagos.

Tabela 3 - Descrição dos produtos adquiridos e preços pagos por meio do PAA e em licitação

\begin{tabular}{|c|c|c|c|c|c|}
\hline Produtos & Tipo & Unidade & $\begin{array}{c}\text { Valor } \\
\text { PAA 2015 } \\
\text { R\$ } \\
\end{array}$ & $\begin{array}{c}\text { Valor } \\
\text { licitação } \\
\text { R\$ } \\
\end{array}$ & $\begin{array}{c}\mathbf{N}^{\mathbf{o}} \\
\text { licitação }\end{array}$ \\
\hline $\begin{array}{l}\text { Abobrinha } \\
\text { convencional }\end{array}$ & Convencional & $\mathrm{Kg}$ & 1,20 & 2,99 & PP 291-15 \\
\hline $\begin{array}{l}\text { Alface } \\
\text { convencional }\end{array}$ & Convencional & $\mathrm{Kg}$ & 2,30 & 1,90 & PP 279-15 \\
\hline $\begin{array}{l}\text { Almeirão } \\
\text { convencional }\end{array}$ & Convencional & $\mathrm{Kg}$ & 2,90 & 1,99 & PP 279-15 \\
\hline Batata doce & Convencional & $\mathrm{Kg}$ & 1,30 & 1,80 & PP 279-15 \\
\hline $\begin{array}{l}\text { Beterraba } \\
\text { convencional }\end{array}$ & Convencional & $\mathrm{Kg}$ & 1,05 & 1,50 & PP 279-15 \\
\hline Bolacha caseira & Convencional & $\mathrm{Kg}$ & 11,74 & 13,50 & PP 291-15 \\
\hline $\begin{array}{l}\text { Brócolis } \\
\text { convencional }\end{array}$ & Convencional & $\mathrm{Kg}$ & 3,00 & 3,95 & PP 279-15 \\
\hline $\begin{array}{l}\text { Carne bovina } \\
\text { dianteira }\end{array}$ & Convencional & $\mathrm{Kg}$ & 8,16 & 7,84 & PP 279-15 \\
\hline $\begin{array}{l}\text { Carne bovina } \\
\text { traseira }\end{array}$ & Convencional & $\mathrm{Kg}$ & 10,36 & 12,65 & PP 279-15 \\
\hline Carne suína & Convencional & $\mathrm{Kg}$ & 6,50 & 6,97 & PP 279-15 \\
\hline $\begin{array}{l}\text { Cebolinha verde } \\
\text { convencional }\end{array}$ & Convencional & $\mathrm{Kg}$ & 4,35 & 6,48 & PP 279-15 \\
\hline $\begin{array}{l}\text { Cenoura } \\
\text { convencional }\end{array}$ & Convencional & $\mathrm{Kg}$ & 1,40 & 2,19 & PP 279-15 \\
\hline $\begin{array}{l}\text { Chuchu } \\
\text { convencional }\end{array}$ & Convencional & $\mathrm{Kg}$ & 0,90 & 4,45 & PP 291-15 \\
\hline $\begin{array}{l}\text { Conserva de } \\
\text { vegetais }^{\mathrm{a}}\end{array}$ & Convencional & $\mathrm{Kg}$ & 5,50 & 17,20 & PP 291-15 \\
\hline $\begin{array}{l}\text { Couve manteiga } \\
\text { convencional }\end{array}$ & Convencional & $\mathrm{Kg}$ & 3,64 & 2,39 & PP 291-15 \\
\hline $\begin{array}{l}\text { Couve flor } \\
\text { convencional }\end{array}$ & Convencional & $\mathrm{Kg}$ & 1,00 & 5,45 & PP 291-15 \\
\hline
\end{tabular}




\begin{tabular}{|c|c|c|c|c|c|}
\hline Cuca caseira & Convencional & $\mathrm{Kg}$ & 7,91 & 12,50 & PP 291-15 \\
\hline Maçã convencional & Convencional & $\mathrm{Kg}$ & 2,80 & 3,00 & PP 279-15 \\
\hline Macarrão caseiro & Convencional & $\mathrm{Kg}$ & 8,21 & 8,58 & PP 279-15 \\
\hline $\begin{array}{l}\text { Mel de abelha } \\
\text { convencional }\end{array}$ & Convencional & $\mathrm{Kg}$ & 10,00 & 16,29 & PP 279-15 \\
\hline $\begin{array}{l}\text { Milho verde } \\
\text { convencional }\end{array}$ & Convencional & $\mathrm{Kg}$ & 3,00 & 8,20 & PP 291-15 \\
\hline Pão caseiro sovado & Convencional & $\mathrm{Kg}$ & 7,02 & 10,79 & PP 291-15 \\
\hline $\begin{array}{l}\text { Pepino } \\
\text { convencional }\end{array}$ & Convencional & $\mathrm{Kg}$ & 1,10 & 2,99 & PP 291-15 \\
\hline $\begin{array}{l}\text { Raiz de mandioca } \\
\text { congelada sem } \\
\text { casca }\end{array}$ & Convencional & $\mathrm{Kg}$ & 2,25 & 2,20 & PP 279-15 \\
\hline $\begin{array}{l}\text { Repolho } \\
\text { convencional }\end{array}$ & Convencional & $\mathrm{Kg}$ & 0,80 & 1,50 & PP 279-15 \\
\hline $\begin{array}{l}\text { Rúcula } \\
\text { convencional }^{\text {a }}\end{array}$ & Convencional & $\mathrm{Kg}$ & 4,00 & 3,30 & PP 291-15 \\
\hline Salsa convencional & Convencional & $\mathrm{Kg}$ & 6,80 & 6,48 & PP 279-15 \\
\hline $\begin{array}{l}\text { Suco de uva } \\
\text { integral }\end{array}$ & Convencional & $\mathrm{L}$ & 6,60 & 10,10 & PP 289-15 \\
\hline $\begin{array}{l}\text { Tomate } \\
\text { convencional }\end{array}$ & Convencional & $\mathrm{Kg}$ & 1,70 & 3,40 & PP 291-15 \\
\hline Vinagre colonial & Convencional & $\mathrm{L}$ & 3,30 & 2,46 & PP 279-15 \\
\hline
\end{tabular}

Nota. PP - Pregão Presencial. ${ }^{a} \mathrm{~A}$ comparação de preços foi realizada com pepino em conserva. ${ }^{a}$ A comparação de preços foi realizada com a unidade de medida maço. Fonte: Elaborado pelos autores, 2016.

Os valores pagos pelo PAA que foram obtidos dos preços publicados pela CONAB são referentes ao período de 01 de julho de 2015 a 30 de junho de 2016. Após identificar os valores pagos pelos produtos adquiridos por meio do PAA e por meio de licitação, obteve-se a diferença entre o valor pago no PAA e o valor pago em licitações realizadas pelo município de Toledo-PR, conforme demonstra a Tabela 4. 
Tabela 4 - Diferença entre os valores pagos por meio do PAA e os valores pagos em licitação

\begin{tabular}{|c|c|c|c|c|c|c|}
\hline Produtos & 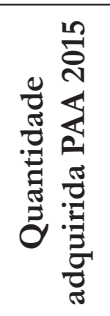 & 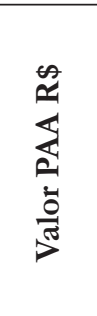 & 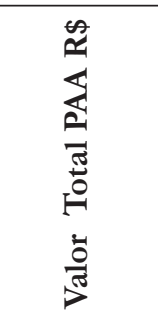 & 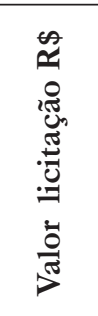 &  &  \\
\hline Tomate convencional & 48 & 1,70 & 81,60 & 3,40 & 163,20 & $-50 \%$ \\
\hline Conserva de vegetais & 36 & 5,50 & 198,00 & 17,20 & 619,20 & $-68 \%$ \\
\hline $\begin{array}{l}\text { Milho verde } \\
\text { convencional }\end{array}$ & 81 & 3,00 & 243,00 & 8,20 & 664,20 & $-63 \%$ \\
\hline $\begin{array}{l}\text { Abobrinha } \\
\text { convencional }\end{array}$ & 214 & 1,20 & 256,80 & 2,99 & 639,86 & $-60 \%$ \\
\hline Pepino convencional & 414 & 1,10 & 455,40 & 2,99 & $1.237,86$ & $-63 \%$ \\
\hline $\begin{array}{l}\text { Couve flor } \\
\text { convencional }\end{array}$ & 669 & 1,00 & 669,00 & 5,45 & $3.646,05$ & $-82 \%$ \\
\hline Chuchu convencional & 945,5 & 0,90 & 850,95 & 4,45 & $4.207,48$ & $-80 \%$ \\
\hline Brócolis convencional & 324,6 & 3,00 & 973,80 & 3,95 & $1.282,17$ & $-24 \%$ \\
\hline Rúcula convencional & 258 & 4,00 & $1.032,00$ & 3,30 & 851,40 & $21 \%$ \\
\hline $\begin{array}{l}\text { Beterraba } \\
\text { convencional }\end{array}$ & 1134,1 & 1,05 & $1.190,81$ & 1,50 & $1.701,15$ & $-30 \%$ \\
\hline $\begin{array}{l}\text { Mel de abelha } \\
\text { convencional }\end{array}$ & 168 & 10,00 & $1.680,00$ & 16,29 & $2.736,72$ & $-39 \%$ \\
\hline $\begin{array}{l}\text { Cebolinha verde } \\
\text { convencional }\end{array}$ & 422,15 & 4,35 & $1.836,35$ & 6,48 & $2.735,53$ & $-33 \%$ \\
\hline Vinagre colonial & 800 & 3,30 & $2.640,00$ & 2,46 & $1.968,00$ & $34 \%$ \\
\hline Cenoura convencional & 2028,2 & 1,40 & $2.839,48$ & 2,19 & $4.441,76$ & $-36 \%$ \\
\hline $\begin{array}{l}\text { Couve manteiga } \\
\text { convencional }\end{array}$ & 866,3 & 3,64 & $3.153,33$ & 2,39 & $2.070,46$ & $52 \%$ \\
\hline Salsa convencional & 494,7 & 6,80 & $3.363,96$ & 6,48 & $3.205,66$ & $5 \%$ \\
\hline Repolho convencional & 5698,1 & 0,80 & $4.558,48$ & 1,50 & $8.547,15$ & $-47 \%$ \\
\hline Maçã convencional & 1785 & 2,80 & $4.998,00$ & 3,00 & $5.355,00$ & $-7 \%$ \\
\hline Cuca caseira & 673 & 7,91 & $5.323,43$ & 12,50 & $8.412,50$ & $-37 \%$ \\
\hline Batata doce & 6024,7 & 1,30 & $7.832,11$ & 1,80 & $10.844,46$ & $-28 \%$ \\
\hline $\begin{array}{l}\text { Almeirão } \\
\text { convencional }\end{array}$ & 3013,7 & 2,90 & $8.739,73$ & 1,99 & $5.997,26$ & $46 \%$ \\
\hline Suco de uva integral & 1384 & 6,60 & $9.134,40$ & 10,10 & $13.978,40$ & $-35 \%$ \\
\hline Bolacha caseira & 920 & 11,74 & $10.800,80$ & 13,50 & $12.420,00$ & $-13 \%$ \\
\hline Alface convencional & 4793,8 & 2,30 & $11.025,74$ & 1,90 & $9.108,22$ & $21 \%$ \\
\hline
\end{tabular}




\begin{tabular}{l|r|c|c|c|c|c}
\hline Pão caseiro sovado & 1604 & 7,02 & $11.260,08$ & 10,79 & $17.307,16$ & $-35 \%$ \\
\hline $\begin{array}{l}\text { Raiz de mandioca } \\
\text { congelada sem casca }\end{array}$ & 5079,8 & 2,25 & $11.429,55$ & 2,20 & $11.175,56$ & $2 \%$ \\
\hline Macarrão caseiro & 2202 & 8,21 & $18.078,42$ & 8,58 & $18.893,16$ & $-4 \%$ \\
\hline Carne suína & 8911 & 6,50 & $57.921,50$ & 6,97 & $62.109,67$ & $-7 \%$ \\
\hline $\begin{array}{l}\text { Carne bovina } \\
\text { dianteira }\end{array}$ & 20135 & 8,16 & $164.301,60$ & 7,84 & $157.858,40$ & $4 \%$ \\
\hline Carne bovina traseira & 20135 & 10,36 & $208.598,60$ & 12,65 & $254.707,75$ & $-18 \%$ \\
\hline Total & & & $555.466,92$ & & $628.885,38$ & $26 \%$ média \\
\hline
\end{tabular}

Fonte: Elaborado pelos autores, 2016.

Ao realizar a comparação entre valores identificou-se que na média total os valores pagos pelos produtos por meio do PAA são $26 \%$ mais baratos do que os valores pagos pelos alimentos adquiridos por meio de licitação. A Figura 1 ilustra o comparativo de valores totais pagos pelos produtos adquiridos pelo PAA em 2015.

Figura 1 - Comparativo de valores totais $(\mathrm{R} \$$ ) pagos pelos produtos adquiridos pelo PAA em 2015

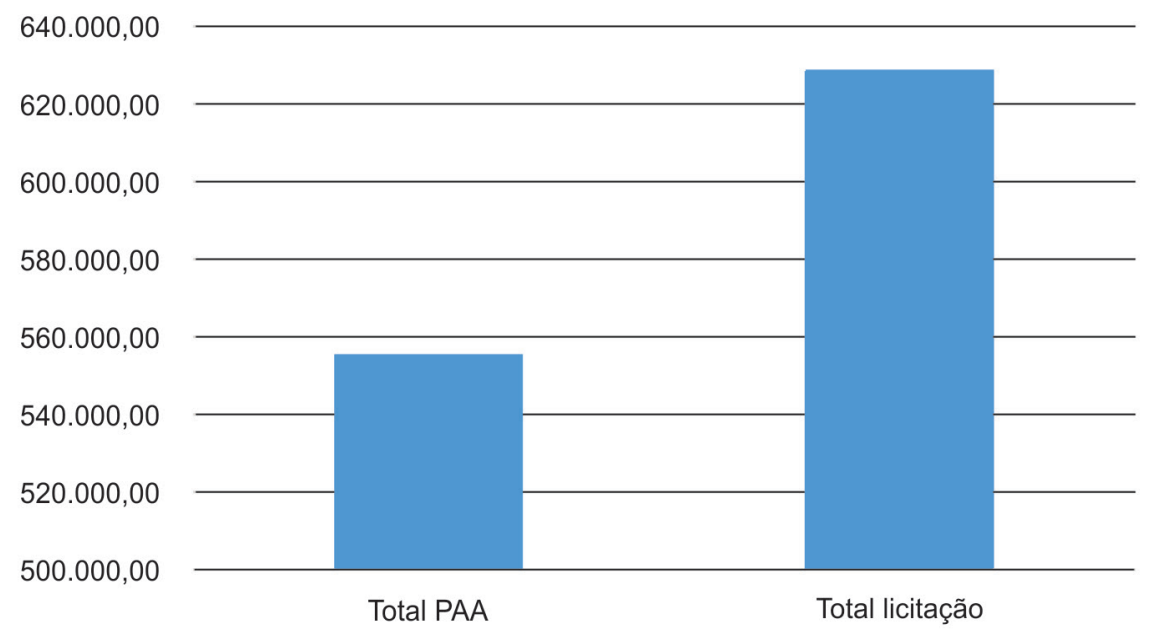

Fonte: Dados da pesquisa, 2016.

Os valores totais indicam diferença de $\mathrm{R} \$ 73.418,46$ entre os itens em comum adquiridos pelo PAA e em licitações. Ressalta-se que as quantidades utilizadas para comparação são aquelas adquiridas pelo PAA no ano de 2015. 
De acordo com Tenório (2011), os subsídios concedidos aos agricultores podem ser divididos em subsídios nos quais os custos são arcados pelos consumidores, e os que são bancados pelo Tesouro, utilizando recursos dos contribuintes. No subsídio pago pelo contribuinte há um gasto do governo com o agricultor por meio de políticas dirigidas, como é o caso da política agrícola para agricultores comerciais e familiares no Brasil. Considerando todos os tipos de subsídios concedidos aos agricultores, um estabelecimento rural brasileiro recebe US\$1,1 mil por ano, o que corresponde a $6 \%$ no Brasil, calculando o total de subsídios em relação à riqueza do setor (valor da produção).

Estudo realizado por Veiga, Silva, Rosa, Conceição e Andrade (2014), que analisou a participação dos agricultores familiares no PAA, constatou que as cotações praticadas pelo PAA são inferiores aos preços praticados pelo mercado, com diferenças em média de $27 \%$ a 31\%. Tais percentuais corroboram os valores identificados nesta pesquisa, nos quais os preços praticados em licitações também são superiores àqueles praticados pelo PAA.

Pesquisa realizada por Pereira e Lourenzani (2014) que analisaram o PAA no município de Tupã-SP, identificou que os produtores que entregam folhosas para o PAA reclamaram pelo fato destes produtos terem os preços baseados pelo peso $(\mathrm{kg})$ e não por maço, como nos demais canais de comercialização. O preço do quilograma da folhosa é, em geral, aquém do preço praticado no mercado, onde é vendido por maço. Os produtores consideram que a tabela de preços utilizada pelo Programa geralmente está abaixo dos preços praticados no mercado, no entanto, este fator também está relacionado à sazonalidade do produto e variação dos preços ao longo do ano.

Assim sendo, verifica-se que na média total os valores pagos pelos produtos por meio do PAA são 26\% menores do que os valores pagos pelos alimentos adquiridos por meio de licitação.

\section{CONSIDERAÇÕES FINAIS}

Ao realizar a comparação de valores pagos no PAA com os valores registrados em licitação, identificamos que na média total os valores pagos pelos produtos por meio do PAA são 26\% mais baixos do que os valores pagos pelos alimentos adquiridos por meio de licitação. Diante destes dados identificou-se que o custo para o setor público ao comprar produtos da agricultura familiar é inferior ao de comprar produtos por meio de licitação, não havendo subsídio. 
Este fator também foi identificado nos valores pagos pelo PAA no município de Toledo-PR, pois dos 30 produtos para os quais foi realizado o comparativo, para apenas 8 produtos o valor pago no PAA é superior ao preço pago em licitações.

Diante do exposto, identifica-se a necessidade de revisão da metodologia de formação de preços dos produtos do PAA, especialmente para os produtos com sazonalidade de produção e grande oscilação de preços durante o ano (como é o caso das hortaliças). Como alternativa poderiam ser realizadas pesquisas de preços trimestrais para atualizar o valor dos produtos, objetivando estimular a participação dos agricultores familiares no programa de aquisição de alimentos, com uma remuneração justa pelos produtos entregues.

Sugere-se para trabalhos futuros estudos sobre a agricultura orgânica realizada no município e na região e quais os incentivos necessários para sua sustentabilidade, além de estudos para verificar a adesão de órgãos públicos na compra de produtos da agricultura familiar.

\section{REFERÊNCIAS}

ABRAMOVAY, R. Paradigmas do capitalismo agrário em questão. 3. ed. São Paulo: EdUSP, 2007.

BCB - Banco Central do Brasil. Programa Nacional de Fortalecimento da Agricultura Familiar - Pronaf, 2015. Disponível em: http://www.bcb.gov. br/?PRONAFFAQ. Acesso em: 11 dez. 2015.

BRASIL. Lei n. 10.696, de 02 de julho de 2003. Dispõe sobre a repactuação e o alongamento de dívidas oriundas de operações de crédito rural, e dá outras providências. Brasília, 2003. Disponível em: http://www.planalto.gov.br/ ccivil_03/_ato2004-2006/2006/lei/111326.htm Acesso em: 11 dez. 2015.

.Lei n. 11.326, de 24 de julho de 2006. Estabelece as diretrizes para a formulação da Política Nacional da Agricultura Familiar e Empreendimentos Familiares Rurais. Brasília, 2006. Disponível em: http://www.planalto.gov.br/ ccivil_03/leis/2003/L10.696.htm Acesso em: 06 dez. 2015.

CARVALHO, M. A. Políticas públicas e competitividade da agricultura. Revista de Economia Política, São Paulo, v. 21, n. 1, p. 117-140, 2001.

CHADAD, F. R.; JANK, M. S.; NAKAHODO, S. N. Repensando as políticas agrícola e agrária do Brasil. Revista Digesto Econômico, São Paulo, p. 1-43, nov./dez. 2006. 
COELHO, C. N. 70 anos de política agrícola no Brasil (1931-2001). Revista de Política Agrícola, São Paulo, v. 10, n. 3, p. 3-58, jul./ago. 2012.

CONAB - Companhia Nacional de Abastecimento. Programa de aquisição de alimentos - PAA - Ações da Conab em 2003, 2003. Disponível em: http://www.conab.gov.br/OlalaCMS/uploads/arquivos/12_07_23_11_43_47_ sumario_paa_2003.pdf. Acesso em: 12 dez. 2015.

EMBRAPA - Empresa Brasileira de Pesquisa Agropecuária. 2014 - Ano Internacional da Agricultura Familiar. Brasília: Embrapa, 2014. Disponível em: https://www.embrapa.br/2014-ano-internacional-da-agricultura-familiar. Acesso em: 26 ago. 2014.

FERREIRA, M. J.; BORSATTO, R. S.; GOMES, R. R. S.; MEIRA, B. C.; BERGAMASCO, S. M. P. P. Programa de Aquisição de Alimentos (PAA) como instrumento para a organização social de agricultores familiares: o caso de Angatuba, Estado de São Paulo. Informações Econômicas, São Paulo, v. 44, n. 1, jan./fev. 2014. Disponível em: ftp:/ /ftp.sp.gov.br/ftpiea/publicacoes/ ie/2014/tec5-0214.pdf. Acesso em: 04 dez. 2015.

GASQUES, J. G.; VIEIRA FILHO, J. E. R.; NAVARRO, Z. A agricultura brasileira: desempenho, desafios e perspectivas. Brasília: Ipea, 2010.

GIL, A. C. Métodos e técnicas de pesquisa social. 5. ed. São Paulo: Atlas, 1999.

.Como elaborar projetos de pesquisa. 4. ed. São Paulo: Atlas, 2002.

GODOY, A. S. Pesquisa qualitativa tipos fundamentais. Revista de Administração de Empresas, São Paulo, v. 35, n. 3, p. 20-29, maio/jun. 1995 a. Introdução à pesquisa qualitativa e suas possibilidades. Revista de Administração de Empresas, São Paulo, v. 35, n. 2, p. 57-63, mar./abr 1995b.

GRISA, C. Políticas públicas para a agricultura familiar no Brasil: produção e institucionalização das ideias. 2012. 280f. Tese (Doutorado em Ciências) Programa de Pós-Graduação de Ciências Sociais em Desenvolvimento, Agricultura e Sociedade da Universidade Federal Rural do Rio de Janeiro, Rio de Janeiro, 2012. GRISA, C.; SCHNEIDER, S. Três gerações de políticas públicas para a agricultura familiar e formas de interação entre sociedade e estado no Brasil. Revista de Economia e Sociologia Rural, Brasília, v. 52, n. 1, p. 125-146, fev. 2014. Disponível em: http://www.scielo.br/pdf/resr/v52s1/a07v52s1.pdf. Acesso em: 11 dez. 2015. 
JUNQUEIRA, C. P.; LIMA, J. F. Políticas públicas para a agricultura familiar no Brasil. Semina: Ciências Sociais e Humanas, Londrina, v. 29, n. 2, p. 159-176, jul./dez. 2008.

MATTEI, L. Programa de aquisição de alimentos da agricultura familiar (PAA): antecedentes, concepção e composição geral do programa. Cadernos do CEAM (UnB), Brasília, v. 7, p. 33-44, 2007. Disponível em: http://www.inagrodf.com. br/revista/index.php/SDR/article/viewFile/20/22. Acesso em: 18 ago. 2014.

MDA - Ministério do Desenvolvimento Agrário. Programa de Aquisição de Alimentos - 10 anos, 2013. Disponível em: http://www.mda.gov.br/sitemda/ sites/sitemda/files/ceazinepdf/CartilhaPAA10anos.pdf Acesso em: 12 dez. 2015.

Ministério do Desenvolvimento Agrário. Saiba como ter a DAP: documento que dá acesso às políticas públicas para agricultores familiares de todo o Brasil, 2015. Disponível em: http://www.mda.gov.br/sitemda/ noticias/saiba-como-ter-dap-documento-que-d $\% \mathrm{C} 3 \% \mathrm{~A} 1$-acesso- $\% \mathrm{C} 3 \% \mathrm{~A} 0$ spol\%C3\%ADticas-p\%C3\%BAblicas-para-agricultores. Acesso em: 14 mar. 2016.

Programa de Aquisição de Alimentos - PAA, 2015. Disponível em:http://mds.gov.br/assuntos/seguranca-alimentar/programa-de-aquisicaode-alimentos-paa. Acesso em: 01 nov. 2015.

Compra institucional, 2013. Disponível em: http://mds.gov.br/ assuntos/seguranca-alimentar/programa-de-aquisicao-de-alimentos-paa/ programa-de-aquisicao-de-alimentos/compra-institucional. Acesso em: 12 dez. 2015.

Programa de Aquisição de Alimentos da agricultura familiar: renda para quem produz e comida na mesa de quem precisa. Ascom, 2012. Disponível em: http://www.mda.gov.br/sitemda/sites/sitemda/files/user_arquivos_64/ CARTILHA_PAA_FINAL.pdf. Acesso em: 03 set. 2015.

MENDONÇA, L. Transformando burocracias para financias os mais pobres: a evolução do Pronaf crédito grupo B. Revista do Serviço Público, Brasília, v. 59, n. 2, p. 187-220, abr./jun. 2008. Disponível em: http://www.spell.org.br/ documentos/ver/35733/transformando-burocracias-para-financiar-os-maispobres--a-evolucao-do-pronaf-credito-grupo-b. Acesso em 11 dez. 2015.

MERA, C. M. P. A população rural na região do Alto Jacuí/RS: análise sob a perspectiva do desenvolvimento agrícola. 2011. Tese (Doutorado em Desenvolvimento Rural) - Programa de Pós-Graduação em Desenvolvimento Rural, Universidade Federal do Rio Grande do Sul, Porto Alegre, 2011. 
MUELLER, C. C. A política agrícola no Brasil: uma visão a longo prazo. Revista de Política Agrícola, São Paulo, v. 19, ed. especial, p. 9-23, jul. 2010.

PEREIRA, M. E. B. G.; LOURENZANI, A. E. B. S. Desafios e perspectivas do programa de aquisição de alimentos no município de Tupã-SP. Ciência e Natura, Santa Maria, v. 36, n. 2, p. 230-240, 2014.

PLEIN, C.; FILIPPI, E. E. O programa de aquisição de alimentos da agricultura familiar (PAA): geração de renda e segurança alimentar. Revista Faz Ciência, Cascavel, v. 14, n. 19, p. 63-86, jan/jun. 2012. Disponível em: http:/ / e-revista.unioeste. br/index.php/fazciencia/article/view/8027/8029. Acesso em: 05 dez. 2015.

PLOEG, J. D. V. D. Dez qualidades da agricultura familiar. Agriculturas: Experiências em Agroecologia, Rio de Janeiro, n. 1, p. 3-14, fev. 2014.

ROMANIELLO, M. M.; ASSIS, T. R. P. Extensão rural e sustentabilidade: guia de estudos. Lavras-MG: UFLA, 2015. Disponível em: http://www.cead. ufla.br/portal/wp-content/uploads/2015/03/Extens\%C3\%A3o-rural-Esutentabilidade.pdf. Acesso em: 08 dez. 2015.

SAGI - Secretaria de Avaliação e Gestão da Informação. PAA Data. Brasília, 2016. Disponível em: http://aplicacoes.mds.gov.br/sagi/paa/visi_paa_geral/ pg_principal.php?url=abertura. Acesso em: 10 set. 2016.

SEED - Secretaria de Estado de Educação. Compra de agricultura familiar é referência nacional. Curitiba, 2015. Disponível em: http://www.educacao. pr.gov.br/modules/noticias/article.php?storyid=5837. Acesso em: 14 mar. 2015.

SILVA, J. G., DEL GROSSI, M. E., FRANÇA, C. G. Fome Zero: a experiência brasileira. Brasília: MDA, 2010.

SOARES, P.; MARTINELLI, S. S.; MELGAREJO, L.; CAVALLI, S. B. Fornecimento de alimentos da agricultura familiar para a alimentação escolar: o exemplo do programa de aquisição de alimentos. Revista Segurança Alimentar e Nutricional, Campinas, v. 20, n. 6, p. 1891-1900, 2013.

SOUZA-ESQUERDO, V. F., BERGAMASCO, S. M. P. P. Análise sobre o acesso aos programas de políticas públicas da agricultura familiar nos municípios do circuito das frutas (SP). Revista de Economia e Sociologia Rural, Brasília, v. 52, n. 1, 205-222, fev. 2014. Disponível em: http://www.scielo.br/pdf/resr/ v52s1/a11v52s1.pdf. Acesso em: 11 dez. 2015. 
STRASSBURG, U.; OLIVEIRA, N. M.; BARCHET, I.; DAL PAI, C.; ILHA, P. C. S.; SHIKIDA, P. F. A. Produção rural e segurança alimentar no Brasil. Revista Brasileira de Desenvolvimento Regional, Blumenau, v. 3, n. 1, p. 55-81, 2015. TENÓRIO, R. Agricultura - do subsídio à política agrícola. Ipea - Desafios do Desenvolvimento, Sãoi Paulo, v. 8, n. 68, p. 36-43, 2011.

VEIGA, W. G. Jr.; SILVA, T.; F. C.; ROSA, E. P.; CONCEIÇÃO, D. B.; ANDRADE, T. R. M. Participação dos agricultores familiares no Programa de Aquisição de Alimentos - PAA. Ceasa Minas: informações de mercado - artigo, 2014.Disponível em: http://www.ceasaminas.com.br/informacoesmercado/ artigos/Artigo_Final_Cedeplar-Participacao\%20_Agricultores_Familiares_no_ PAA.pdf. Acesso em: 11 set. 2016.

ZANINI, E. O.; SCHNEIDER, M. B. Restaurantes populares em Toledo: um programa de desenvolvimento. Economia e Desenvolvimento, João Pessoa, v. 27, n. 2, p. 243-256, jul./dez. 2015. 